\title{
EFISIENSI PENYERAPAN PHOSPAT LIMBAH LAUNDRY MENGGUNAKAN KANGKUNG AIR (Ipomoea aquatic forsk) DAN JERINGAU (Acorus calamus)
}

\author{
Fitri Dewi, M. Faisal, Mariana \\ Program Studi Magister Teknik Kimia, \\ Universitas Syiah Kuala, Darussalam, Banda Aceh, 23111, Indonesia \\ Email: mfaisal@unsyiah.ac.id
}

\begin{abstract}
Abstrak
Limbah laundry mengandung konsentrasi phosphat yang tinggi melebihi kadar phospat yang diijinkan oleh PP No 82 tahun 2001 tentang Pengelolaan Kualitas Air Dan Pengendalian Pencemaran Air yaitu 0,2 mg/L. Apabila limbah cair tersebut langsung dibuang ke selokan atau badan air tanpa pengolahan maka dapat menimbulkan pencemaran air dan mengakibatkan eutrofikasi. Diantara tanaman yang digunakan untuk menyerap phospat adalah kangkung air (Ipomoea aquatica forsk) dan jeringau (Acorus calamus 1). Penelitian ini bertujuan untuk mengetahui tingkat efisiensi penyerapan phospat oleh tanaman kangkung air dan jeringau. Penelitian dilakukan dengan sistem batch. Hasil penelitian menunjukkan bahwa efisiensi penurunan phospat oleh kangkung air sebesar 41,61\% dan pada jeringau 53,75\%.
\end{abstract}

Kata kunci : air pencucian pakaian, fitoremediasi, kangkung air, jeringau, phospat, $\mathrm{pH}$, kekeruhan

\begin{abstract}
Laundry waste contains high phosphate concentrations that exceeding levels in Regulation No. 82 of 2001 about Water Quality Management and Control of Water Pollution. When the waste is directly discharged into the sewers or river without treatment, it can cause water pollution and lead to eutrophication. Water spinach (Ipomoea aquatica Forsk) and Jeringau (Acorus Calamus l) might be use to absorb phosphate in laundry waste. The aim of this research is to investigate the efficiency of phosphate absorption by using water spinach and Jeringau. The experiments were carried out in a batch system. The results showed that the reduction efficiency of phosphate by Water spinach and Jeringau was $41.61 \%$ and $53.75 \%$, respectively.
\end{abstract}

Key words : Laundry, phytoremediation, water spinach, jeringau,Phosphate.

\section{Pendahuluan}

Industri pencucian pakaian (laundry) menghasilkan limbah cair yang mengandung konsentrasi phosphat yang tinggi melebihi kadar phospat yang diijinkan yaitu $0,2 \mathrm{mg} / \mathrm{L}$ (PP No 82 tahun 2001), sehingga bila limbah cair tersebut langsung dibuang ke selokan atau badan air tanpa pengolahan maka dapat menimbulkan pencemaran air dan mengakibatkan eutrofikasi. Limbah yang masuk mencemari badan air dapat mengakibatkan kekeruhan dan menghalangi sinar matahari masuk ke dalam air menurut Ananda [2]. Hal ini juga dapat mempengaruhi keberlangsungan kehidupan biota yang ada dibadan air tersebut.

Dalam penelitian ini digunakan tumbuhan kangkung air (Ipomoea aquatica forsk) dan jeringau (Acorus calamus L) untuk mengurangi kandungan phosphat dalam limbah pencucian baju. Tujuan dari penelitian ini adalah untuk mengetahui efektifitas dan efisiensi penyerapan phospat oleh kangkung air dan jeringau dalam air limbah pencucian pakaian (laundry).

\section{Teori}

Limbah laundry yang mengandung phosphat yang tinggi. Phosphat berasal dari Sodium Tripoly Phosphate (STPP) yang merupakan bahan builder yang sangat penting setelah surfaktan. STPP berfungsi untuk menghilangkan mineral kesadahan dalam air sehingga deterjen dapat bekerja optimal. $\mathrm{PO}_{4}$ yang berlebih dalam air akan menyebabkan eutrofikasi dan berujung pada kerusakan ekosistem perairan.

Salah satu metode pengolahan untuk menanggulangi pencemaran air yaitu dengan menggunakan tanaman air sebagai media untuk menyerap limbah. sehingga dapat menetralisir zat - zat tertentu dalam air dan tanah yang disebut fitoremediasi. Menurut Juhaeti, dkk [5] banyak tumbuhan yang menyerap logam dalam jumlah yang bervariasi, tetapi beberapa tumbuhan mampu mengakumulasi unsur logam tertentu dalam konsentrasi yang cukup tinggi. Keberhasilan penerapan fitoremediasi untuk menghilangkan logam berat dan kontaminan 
organik dalam tanah telah diteliti oleh beberapa peneliti sebelumnya [7-10].

Ada enam tahapan proses yang terjadi ketika fitoremedisasi berlangsung, yaitu :

1. Phytoacumulation merupakan proses dimana tumbuhan menarik zat pencemar dari media sehingga terkumpul pada bagian akar tumbuhan

2. Rhizofiltration yaitu penyerapan zat pencemar dan membuatnya mengendap di akar tumbuhan

3. Phytostabilization yaitu menstabilkan zat zat yang tidak dapat terserap masuk ke dalam akar tumbuhan

4. Rhyzodegradation merupakan tahapan penguraian zat pencemar oleh mikroba yang terdapat pada bagian akar tumbuhan

5. Phytodegradation yaitu menguraikan zat pencemar yang memiliki rantai molekul yang kompleks menjadi rantai yang lebih sederhana sehingga dapat dimanfaatkan bagi pertumbuhan hidup tanaman itu sendiri

6. Phytopvolatization yaitu menguapkan zat pencemar yang telah diurai ke atmosfer [4].

\section{Metodologi}

Sampel yang digunakan dalam penelitian ini diambil dari usaha laundry di Darussalam, Banda aceh. Tanaman yang digunakan dalam penelitian ini adalah kangkung air dan jeringau yang diambil dipersawahan dan rawa - rawa dengan panjang tanaman $30 \mathrm{~cm}$ untuk kangkung air dan $50 \mathrm{~cm}$ untuk jeringau. Kemudian tanaman tersebut masing - masing ditimbang sebanyak 200 gr/reaktor. Kemudian tanaman tersebut dimasukan ke dalam reaktor yang berukuran panjang $30 \mathrm{~cm}$, lebar $23 \mathrm{~cm}$, tinggi $30 \mathrm{~cm}$ dan berisikan limbah cair laundry sebanyak 2L/reaktor. Kemudian pengukuran parameter $\mathrm{pH}$, phosfat, kekeruhan pada hari ke $0,2,4,6,8$ dan 10. Fitoremediasi limbah laundry ditampilkan pada Gambar 1.

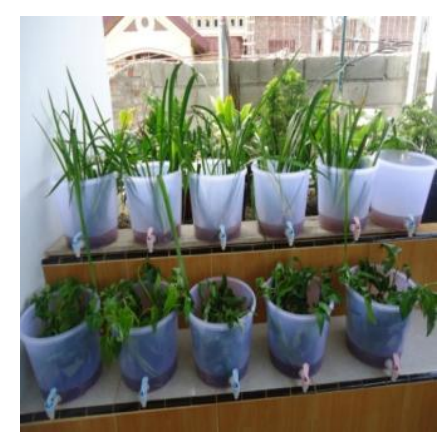

Gambar 1. Fitoremediasi oleh Tanaman Kangkung Air dan Jeringau

\section{Hasil dan Pembahasan}

Karakteristik sampel limbah laundry yang digunakan sebagai sampel ditampilkan pada Tabel 1. Pengujian parameter $\mathrm{pH}$, kekeruhan dan konsentrasi phospat dilakukan pada hari ke $0,2,4,6,8$ dan 10.

\section{Tabel 1. Karakteristik Sampel}

\begin{tabular}{|c|l|c|c|c|}
\hline No & Parameter Uji & Satuan & $\begin{array}{c}\text { Baku } \\
\text { Mutu }\end{array}$ & $\begin{array}{c}\text { Hasil } \\
\text { Uji }\end{array}$ \\
\hline 1. & pH & - & $6-9$ & 9,97 \\
\hline 2. & Kekeruhan & NTU & - & 906 \\
\hline 3. & $\begin{array}{l}\text { Phospat } \\
\left(\mathrm{PO}_{4}\right)\end{array}$ & $\mathrm{Mg} / \mathrm{L}$ & 0,2 & 173 \\
\hline
\end{tabular}

Hasil pengujian pada Tabel 1 menunjukkan bahwa $\mathrm{pH}$, kekeruhan dan phospat dalam air limbah laundry tidak memenuhi baku mutu menurut PP No. 82 Tahun 2001 sehingga dapat mencemari bila langsung dibuang ke badan air tanpa adanya pengolahan untuk meminimalisasi kandungan limbahnya. Konsentrasi parameter sampel yang diperoleh sangat tinggi bila dibandingkan dengan hasil penelitian Ananda [2] yang ditampilkan pada Tabel 2 yang menunjukkan bahwa konsentrasi phospat, melebihi baku mutu yang diijinkan, sehingga limbah laundry ini memerlukan pengolahan terlebih dahulu untuk menurunkan konsentrasi paramaternya dengan fitoremediasi menggunakan tanaman eceng gondok.

Tabel 2. Karakteristik sampel Laundry

\begin{tabular}{|c|l|c|c|c|}
\hline No & $\begin{array}{l}\text { Parameter } \\
\text { Uji }\end{array}$ & Satuan & $\begin{array}{c}\text { Baku } \\
\text { Mutu }\end{array}$ & $\begin{array}{c}\text { Hasil } \\
\text { Uji }\end{array}$ \\
\hline 1. & Suhu & ${ }^{\circ} \mathrm{C}$ & - & 25 \\
\hline 2. & TSS & $\mathrm{Mg} / \mathrm{L}$ & 200 & 180 \\
\hline 3. & $\mathrm{pH}$ & - & $6-9$ & 7,65 \\
\hline 4. & $\begin{array}{l}\text { Phospat } \\
\left(\mathrm{PO}_{4}\right)\end{array}$ & $\mathrm{Mg} / \mathrm{L}$ & 0,2 & 29,625 \\
\hline
\end{tabular}

\section{Karakteristik limbah laundry setelah fitoremediasi}

a. $\mathbf{p H}$

Berdasarkan pemeriksaan $\mathrm{pH}$ pada sampel air maka diperoleh nilai $\mathrm{pH}$ yang berangsurangsur turun dari 9,97 ke 7 pada hari ke 10 . Grafik persentase penurunan $\mathrm{pH}$ ditampilkan pada Gambar 2. 


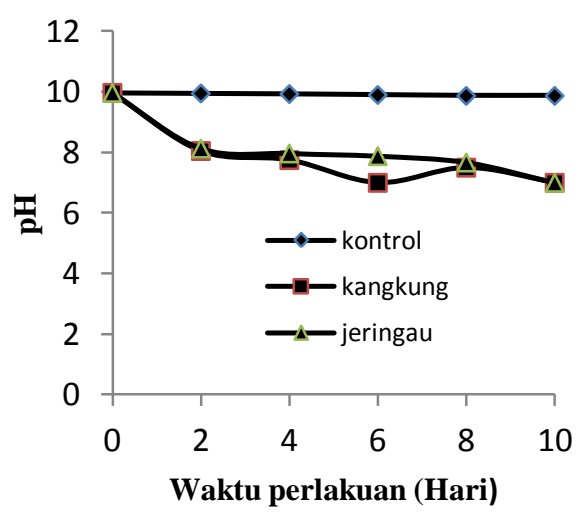

\section{Gambar 2. pH setelah Fitoremediasi}

Gambar 2 memperlihatkan bahwa proses fitoremediasi oleh tumbuhan kangkung air dan jeringau dapat menurunkan $\mathrm{pH}$ limbah laundry yang semula sangat asam menjadi netral. Hal ini sesuai dengan hasil penelitian [1] yang menyatakan bahwa fitoremediasi jeringau dapat menghasilkan $\mathrm{pH}$ netral yaitu 7,1, sehingga dalam pengolahan limbah laundry tidak diperlukan lagi proses netralisasi untuk memperoleh $\mathrm{pH}$ ideal. Penurunan $\mathrm{pH}$ disertai dengan penurunan phospat, hal ini juga sesuai dengan penelitian Ananda [2] yang menyatakan pada hari ke $10 \mathrm{pH}$ menjadi ideal yaitu 8 dan phospat menurun hingga $8,4 \mathrm{Mg} / \mathrm{L}$.

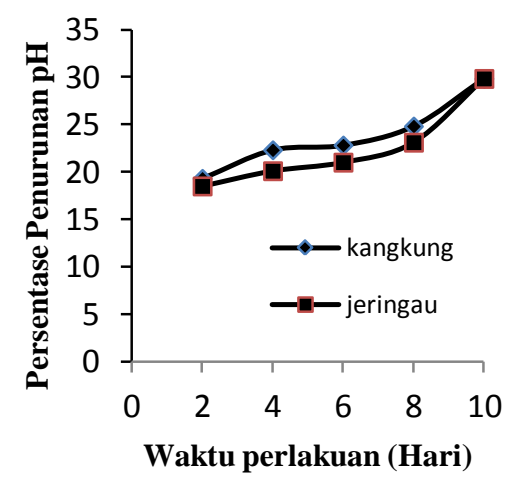

\section{Gambar 3. Persentase Penurunan pH}

Gambar 3 menunjukkan persentase Efisiensi penurunan $\mathrm{pH}$ yang semakin lama semakin netral. Persentase efisiensi penurunan pH adalah sebesar 29,7\% pada hari ke 10. Bila dalam suatu kondisi terjadi $\mathrm{pH}$ yang tidak netral maka dapat menggangu kinerja biologis dalam proses penjernihan badan air. Pada umumnya bakteri tumbuh dengan optimal pada $\mathrm{pH}$ netral dan alkalis, sehingga proses dekomposisi bahan organik membutuhkan waktu yang singkat menurut Nur Ulfah [6].

\section{b. Kekeruhan}

Nilai kekeruhan pada awalnya adalah 906 NTU yang berangsur - angsur turun menjadi 125 NTU pada reaktor kangkung air dan 138,5 NTU pada reaktor jeringau. Kekeruhan dan persentase efisiensi penyerapannya ditampilkan pada Gambar 4 dan 5.

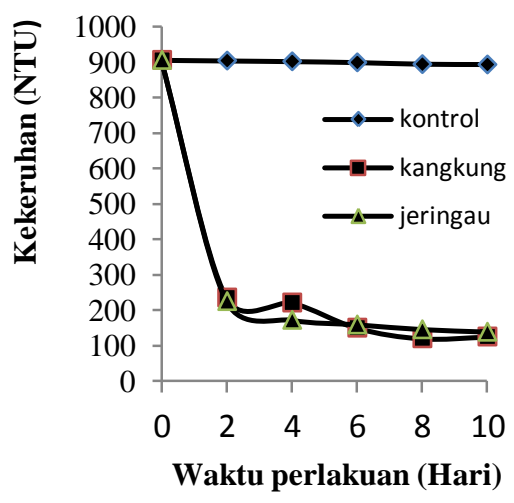

Gambar 4. Penurunan Kekeruhan

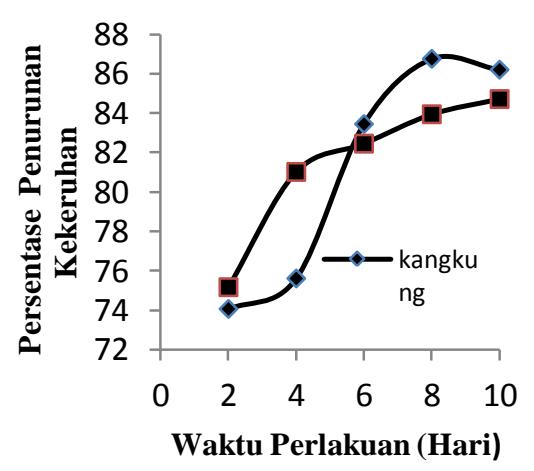

\section{Gambar 5. Persentase Penurunan Kekeruhan}

Hasil penelitian Ikawati, dkk [3] menyatakan bahwa bila tingkat kekeruhan badan air $\geq 20$ NTU masih berbahaya bagi organisme air tersebut, karena dapat merusak aktivitas dan proses metabolisme organisme tersebut.

\section{c. Phospat}

Dari keseluruhan perlakuan fitoremediasi pada limbah laundry menunjukkan adanya 
penurunan konsentrasi phospat dari hari ke 2 sampai hari ke 10. Konsentrai awal phospat sebesar $173 \mathrm{Mg} / \mathrm{L}$ berangsur - angsur turun sampai hari ke 10 , yaitu $101 \mathrm{Mg} / \mathrm{L}$ pada reaktor kangkung air dan $80 \mathrm{Mg} / \mathrm{L}$ pada reaktor jeringau. Konsentrasi dan persentase penurunan phospat ditampilkan pada Gambar 6 dan 7 .

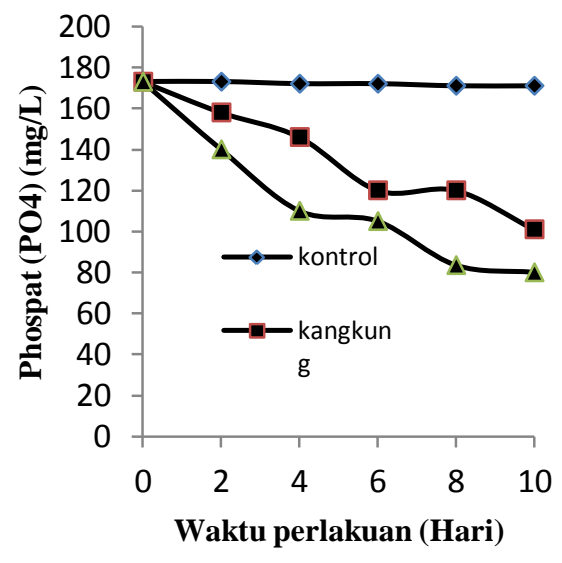

\section{Gambar 6. Penyerapan Phospat}

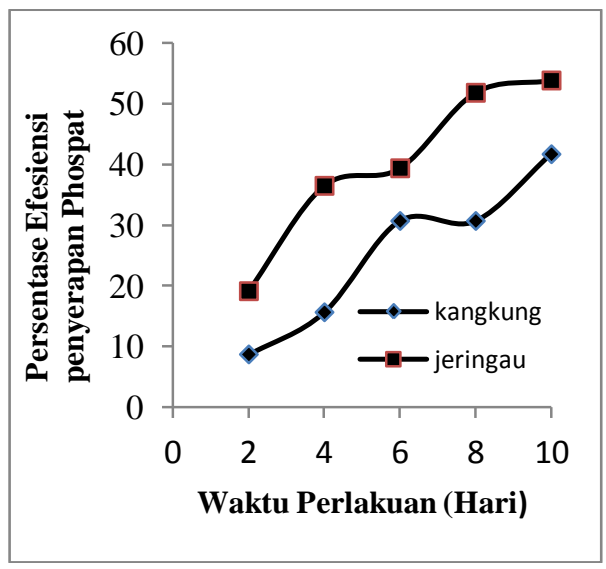

\section{Gambar 7. Efisiensi Penyerapan Phospat}

Dari Gambar 6 dapat dilihat bahwa teknik fitoremediasi yang melibatkan tanaman kangkung air dan jeringau dapat menurunkan konsentrasi phospat dalam limbah laundry. Gambar 7 memperlihatkan persentase efisiensi penurunan phospat. Total efisiensi penyerapan phospat pada hari ke 10 oleh kangkung air sebesar 41,61 \% sedangkan jeringau 53,75\%, sehingga dapat ditarik kesimpulan bahwa tanaman jeringau lebih maksimal menyerap phospat dibandingkan dengan kangkung air. Penelitian menurut Ananda [2] menyatakan bahwa fitoremediasi menggunakan tanaman eceng gondok dapat menurunkan kandungan phospat yang awalnya $16,42 \mathrm{Mg} / \mathrm{L}$ sampai 2,8 $\mathrm{Mg} / \mathrm{L}$ pada limbah laundry pada hari ke 20 .

\section{Kesimpulan}

1. Fitoremediasi dengan tanaman kangkung air dan jeringau pada limbah pencucian pakaian dapat menurunkan $\mathrm{pH}$ menjadi netral (6-9).

2. Penggunaan kangkung air dan jeringau dapat menurunkan kekeruhan sebesar 86, $2 \%$ dan $84,7 \%$.

3. Efisiensi penurunan phospat oleh kangkung air dan jeringau sebesar 53,75\%.

\section{Daftar Pustaka}

[1] Amansyah, M., Daud. A., Bachry. N. N., Fakultas Kesehatan Masyarakat, Universitas Hasanuddin. 2012.

[2] Ananda, C.,S, Sutisna, M., Pharmawati, K., Jurusan Teknik Lingkungan, Itenas, Bandung. 2013.

[3] Ikawati, S., Zulfikar, A., Azizah, D., Program Studi Manajemen Sumberdaya Perairan, Fakultas Ilmu Kelautan dan Perikanan, Universitas Maritim Raja Ali Haji. 2013.

[4] Irhamni, Tesis, Universitas Syiah Kuala, 2009.

[5] Juhaeti, T., Fauzia. S, Nuril. H., Lembaga Ilmu Pengetahuan Indonesia (LIPI), Bogor. 2004.

[6] Nur Ulfah, W., Departemen Manajemen Sumberdaya Perairan, Fakultas Perikanan dan Ilmu Kelautan, Institut Pertanian Bogor. 2009.

[7] Pavas. Paulo. JC., Pratas. J., Prasad. M.N.V., Journal Science of the Total Environment 433 : 390-397. 2012.

[8] Panz. K., Miksch. K., Journal of Environmental Management 113 : 85 - 92. 2012.

[9] Pavas. Paulo. JC., Pratas. J., Varum. M., D’Sauza. R., Paul. M.S, Journal Science of the Total Environment 470-471 : 9931002. 2014.

[10] Sung. W. K., Chiu. L. H., Shen. H. L., Ye chen. P., Hsien. S.C., Journal Chemosphere 72 : 666 - 672. 2008. 